\title{
Recovery from bone loss, diminished mineral density and strength in mice after treatment with steroidal and nonsteroidal anti-inflammatory drugs by injection of exosomes enriched with agomir miRNAs
}

Tomasz P. Lehmann*1, a, Ewa Pruszyńska-Oszmałek ${ }^{2, b}$, Paweł Kołodziejski ${ }^{2, c}$, Magdalena Wojtków ${ }^{3, \text { d }}$, Celina Pezowicz ${ }^{3,}$, Mirosław Szybowicz ${ }^{4, f}$, Paweł Jagodzinski, g, Marek Nowicki ${ }^{5, h}$, Aleksandra Trzaskowska ${ }^{6, i}$, Sławomir Mielcarek ${ }^{6, j}$, Maciej Głowacki ${ }^{7, k}$

${ }^{1}$ Department of Biochemistry and Molecular Biology, Poznan University of Medical Sciences, Poland

${ }^{2}$ Department of Animal Physiology and Biochemistry, Poznan University of Life Sciences, Poland

${ }^{3}$ Department of Biomedical Engineering, Mechatronics and Theory of Mechanisms, Wroclaw University of Science and Technology, Poland

${ }^{4}$ Institute of Materials Research and Quantum Engineering, Faculty of Technical Physics, Poznan University of Technology, Poland

${ }^{5}$ Wielkopolska Centre for Advanced Technologies, Poznań, Poland

${ }^{6}$ Crystal Physics Division, Faculty of Physics, Adam Mickiewicz University, Poznań, Poland

${ }^{7}$ Department of Paediatric Orthopaedics and Traumatology, Poznan University of Medical Sciences, Poland

* Corresponding Autor: Tomasz P. Lehmann, Department of Biochemistry and Molecular Biology, Poznan University of Medical Sciences, 6 Swiecickiego Street, 60-781 Poznań, Poland email: tlehmann@ump.edu.pl

a (iD) https://orcid.org/0000-0001-8445-0970

b (iD https://orcid.org/0000-0002-7182-6905

c (iD) https://orcid.org/0000-0002-7941-0955

d (iD https://orcid.org/0000-0003-0082-0386

e (iD https://orcid.org/0000-0002-3516-4764

$f$ (D) https://orcid.org/0000-0001-8933-571X

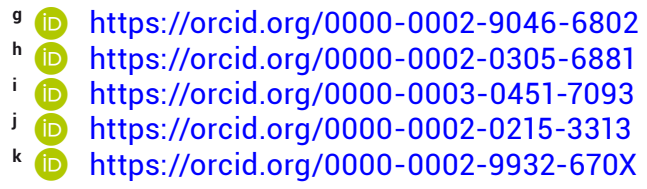

\section{ABSTRACT}

The project "Recovery from bone loss, diminished mineral density and strength in mice after treatment with steroidal and nonsteroidal anti-inflammatory drugs by injection of exosomes enriched with agomir miRNAs" is an animal experiment project, and an attempt to apply small RNA strands to reverse the harmful effects of anti-inflammatory drugs. Patients chronically treated with an anti-inflammatory drug suffer from musculoskeletal side effects, including reversed mineralisation and disabled bone fracture healing. The aims of the study are to measure changes in bone mineral density and bone strength in mice treated with methylprednisolone or diclofenac in combination with treadmill exercise. The reversal of the negative effects of these drugs will be assayed using modified miRNA agomir. Bones obtained from the treated mice will be analysed using micro-CT, dynamic mechanical analysis (DMA), nanoindentation, Raman spectroscopy and gene expression. We expect to find specific miRNA counteracting the demineralisation of the mice bones caused by methylprednisolone or diclofenac.

Keywords: methylprednisolone, diclofenac, miRNA, bone, exercise, bone strenght. 


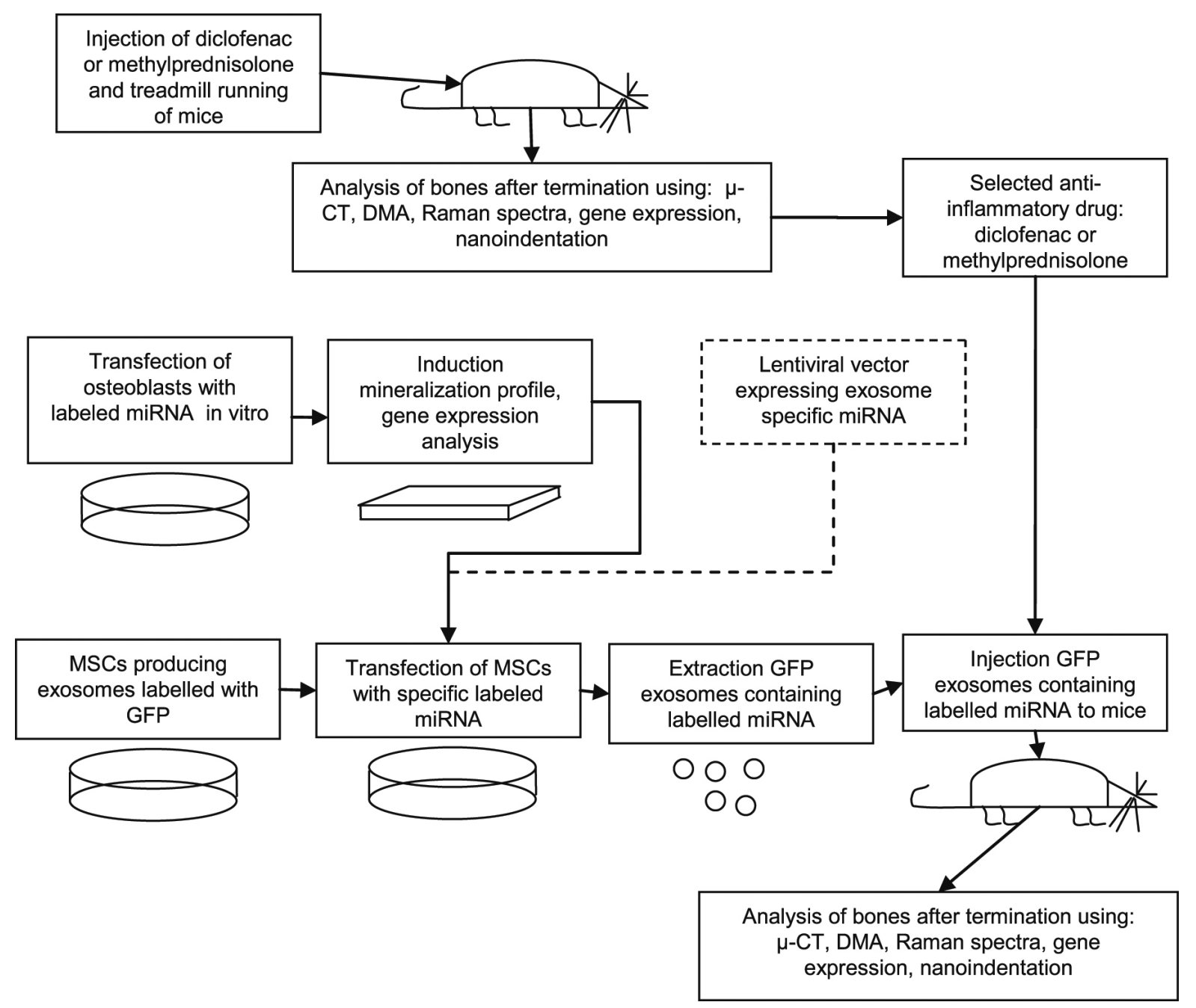

Figure 1. A general overview of the project

\section{General information}

The project "Recovery from bone loss, diminished mineral density and strength in mice after treatment with steroidal and nonsteroidal anti-inflammatory drugs by injection of exosomes enriched with agomir miRNAs" was awarded by the Polish National Science Center (NCN) under project number: 2016/21/B/NZ7/02748 (OPUS 11 competition). The duration of the grant is 36 months, from $3^{\text {rd }}$ March 2017 to $2^{\text {nd }}$ March 2020. The contract between NCN and Poznan University of Medical Sciences (PUMS), Poland, was signed on 3 March 2017.

\section{Management}

The Principal Investigator of the grant is professor Maciej Głowacki, Department of Paediatric
Orthopaedics and Traumatology, Poznan University of Medical Sciences.

The main Co-Investigator of the grant is $d r$ Tomasz Lehmann Department of Biochemistry and Molecular Biology, Poznan University of Medical Sciences. In addition, the Co-Investigators in alphabetical order are: prof. $d r$ hab. Paweł Jagodzinski, dr Paweł Kołodziejski, prof. dr hab. Sławomir Mielcarek, dr Marek Nowicki, prof. dr hab. Celina Pezowicz, dr Ewa Pruszyńska-Oszmałek, prof. dr hab. Sławomir Szybowicz, dr hab. Aleksandra Trzaskowska, and dr Magdalena Wojtków.

\section{Ethics}

The experiments were approved by the Local Ethics Commission for Investigation on Animals, Poznań University of Life Sciences, 14 $4^{\text {th }}$ July 2017. 


\section{Finance}

The total amount of grant funding is PLN 620,750 (about 145,000 Euro). The amount of funding in the first year is PLN 243,750 (about 56,937 Euro). Grant funds were designed to purchase animals, equipment, and reagents, and also to cover the personnel costs of the project participants, and the dissemination of the research results, such as publications in peer reviewed journals.

\section{Research Project Objectives}

Rehabilitation after hip replacement, bone fracture healing, and other orthopedic operations require the application of steroidal and nonsteroidal anti-inflammatory drugs (NSAIDs). In bones, glucocorticoids (GC) act on osteoblast cells reversing the mineralisation of the extracellular matrix [1]. When treated with these steroids, patients suffer from musculoskeletal side effects; mainly accelerated bone loss [2]. Consequently, fractures of the femur and spine are a frequent consequence of GC treatment in $30-50 \%$ of patients. This medication causes apoptosis of osteoblasts and osteocytes and depresses osteoblastic function, simultaneously acting on the expression of many genes in the bones [3].

Chronic inflammation triggers bone loss as a result of fractures, infection, non-unions, arthritis, osteoporosis, metabolic bone disease, tumours and post-operative complications [4]. The production of pro-inflammatory prostaglandins are a required component of normal fracture-healing, implicating that cyclooxygenase inhibitors such as non-steroidal anti-inflammatory drugs (NSAIDs) may directly influence osseous repair [5]. NSAIDs interfere in the rehabilitation of post-traumatic bone fractures and post-operative healing of bones after hip replacement and other types of orthopedic surgery.

Mineralisation is the main factor of bone strength and mechanical resistance, the application of anti-inflammatory drugs diminishes the mechanical properties of bone $[6,7]$.

Several strategies have been proposed to assist in the recovery of the adverse effects of analgesic treatment on the skeletal system [8]. Calcium, vitamin D supplementation and bis- phosphonates treatment are the most appropriate strategies to prevent glucocorticoid-induced bone-loss in patients [9]. Another method to diminish the side effects is hormone replacement therapy for women (HRT) applied to diminish the osteoporosis outcome [10]. The long-lasting strategy that can delay the onset of GC-induced osteoporosis is exercise. Osteogenesis is induced by exercise and promotes bone anabolism. However, there are no current data comparing training with concomitant analgesic pharmacological intervention [11, 12]. There is little data on the impact of the composed effect of NSAIDs or GC on trained mice, and ambiguous results of studies showing the impact of physical exercises on bone strength.

New experimental approaches take advantage of knowledge covering gene expression and the role of small nucleic acid oligonucleotides (miRNAs) in the homeostasis of the bone microenvironment [13]. As a result of these studies, several miRNA were proposed as potential anti-bone-loss agents.

In our project, we intend to follow this research using microcomputer tomography $(\mu-C T)$ for detailed examination of the bone structure in situ. We also want to extend this approach by a complementary study of bones using dynamic mechanical analysis (DMA), gene expression, nanoindentation, and Raman spectroscopy. Such an approach to ex vivo studies has so far rarely been applied to mice treated with GC s, and NSAIDs in combination with exercise. There is also a small number of papers describing $\mu-C T$, mechanical and histological methods applied to assess bone strength with miRNA treatment.

\section{Aim}

The aims of the study are a) to treat mice with methylprednisolone or diclofenac and measure changes in bone mineral density and bone strength, b) to produce exosomes containing the modified miRNA agomir by the synthesis of modified miRNA agomir (miR-29a or miR216a), and the transfection of mouse mesenchymal stem cells, and c) by injecting the exosomes into mice, to promote bone re-mineralisation and increase the bone strength. 


\section{Research Plan and Basic Concept}

Step I

Estimation of bone mineralisation and mechanical strength in mice treated with diclofenac, and methylprednisolone in combination with exercise

, Mice treatment with diclofenac or methylprednisolone for four weeks in combination with enforced treadmill exercise.

, Mice termination, analysis of bones by micro-CT dynamic mechanical analysis (DMA), nanoindentation, Raman spectroscopy and gene expression (Figure 1).

\section{Step II}

Selection of miRNA with the highest remineralisation potential using mouse osteoblasts in culture

, Synthesis of oligonucleotides miR-29a, miR216a, and miR-150.

- Transfection of osteoblast cell line MC3T3-E1 by oligonucleotides. After four days of incubation, cells will be harvested and the mRNA will be extracted.

> Analysis of mRNA profile for 10 genes involved in mineralisation, including genes regulated by miR-29a and miR-216a.

, Specific miRNA which strongly reverses the effect of the anti-inflammatory drug will be selected for further studies.

, Selected miRNA will be labelled with Cy5 and transfected into MC3T3-E1 cells.

, Extraction of exosomes and miRNA from exosomes. Measurement of selected miRNA in exosomes by RT-PCR.

Step III

Production of exosomes with selected miRNA in bone marrow mesenchymal stem cells

, Selected miRNA will be labelled with Cy5 and transfected into MSCs.

, Transfection of MSCs with the plasmid system introducing GFP to the exosomes.

, Extraction of labelled exosomes and miRNA from the exosomes. Measurement of the selected miRNA in the exosomes by RT-PCR.

, Treatment of МСЗТ3 with the labelled exosomes with miRNA, analysis of gene expression.

\section{Step IV}

Injection of exosomes into mice treated with anti-inflammatory drug
Injection of labelled exosomes into mice treated with the anti-inflammatory drug.

, Treatment of the mice with diclofenac or methylprednisolone for 4 weeks.

- Mouse termination, and analysis of bones with fluorescent microscope, by $\mu-C T$ dynamic mechanical analysis (DMA), nanoindentation, Raman spectroscopy, and gene expression.

\section{Step V}

Vector-driven expression of selected miRNA in bone marrow mesenchymal stem cells and injection into mice treated with anti-inflammatory drug

, Construction of plasmid lentiviral vector bearing the selected miRNA.

, Transduction of MSCs with lentivirus encoding the selected miRNA and extraction of exosomes.

, Injection of the labelled exosomes with the selected miRNA into mice and treatment of the mice with the anti-inflammatory drug for 4 weeks.

, Mouse termination, analysis of bones by $\mu-\mathrm{CT}$, DMA, nanoindentation, Raman spectroscopy, and gene expression.

, Analysis of the mRNA profile in the bones for 10 key genes involved in mineralisation.

, Incubation of human femur explants with osteoporosis treatment with the labelled exosomes. Analysis of the mRNA profile in the bones.

\section{Research Methodology}

1. Animals. 8-week-old female mice will be randomly divided into six treatment groups $(n=10)$. The mice will be intraperitoneally injected with $5 \mathrm{mg} / \mathrm{kg} /$ day of methylprednisolone or diclofenac. After four weeks, these mice will be terminated by an overdose of Pentothal. The bones (femurs and tibias) will be obtained.

2. Enforced treadmill exercises. The animals will be subjected to a running procedure using a rodent horizontal treadmill at $12 \mathrm{~m} / \mathrm{min}$. for $30 \mathrm{~min} . /$ day (5\% gradient).

3. Dynamic Mechanical Analysis (DMA) is a physical method used to measure the mechanical properties of materials. DMA makes it possible to specify a storage modulus, a loss modulus 
and a composite modulus. These moduli enable a bone sample's the ability to retain energy to be determined along with the ratio of its absorption.

4. Micro-computed tomography $(\mu-\mathrm{CT})$ To measure the microstructure of the bone, the bone mineral density, and other parameters, the samples will be analysed using a $\mu$-CT scanner and associated analysis software.

5. Raman spectroscopic analysis of mouse tibia chemical composition. In order to determine the changes in the mineral and organic structure of the compacted tissue of the tibial bones of the mice, Raman light scattering studies will be conducted using a confocal Raman microscope. It will allow the index of bone mineralisation MI (mineralisation index) to be determined. In order to investigate the quantitative changes in a mineral component, the ratio of integral intensities of these bands $\left(\mathrm{CO}_{3}{ }^{2-} /\right.$ $\mathrm{PO}_{4}{ }^{3-}$ ), the $\mathrm{Cl}$ (carbonate index) will be used.

6. Nanoindenter micromechanical analysis. Optical measurements will be performed using a laser confocal measuring microscope. The indenter registers the force versus depth curve by making an indent. During the test, the force applied to the indenter tip oscillates sinusoidally, which allows a quasi-continuous determination of the hardness value and bone elasticity module. The measurement will be carried out for a depth of indentation between 400 and $2400 \mathrm{~nm}$ from the cross-sectional area. The hardness and modulus of elasticity will be determined at 10-15 points in the middle of the cross-section of the bone wall on each bone.

7. Cell lines. A multipotent immortalised mouse mesenchymal cell line will be cultured in mesenchymal stem cell culture media according to the protocol of the cell line supplier.

The MC3T3-E1 mouse osteoblast cell line will be cultured in a mineralisation medium. The cultures will be induced to differentiate by transferring the cells, after detachment, into a culture medium supplemented with L-ascorbic acid and glycerol phosphate at final concentrations of $50 \mathrm{mg} / \mathrm{ml}$ and $10 \mathrm{mM}$, respectively.

8. Oligonucleotide synthesis, labelling Cy5. Synthetic oligonucleotides, agomirs, antagomirs and their Cy5-labelled counterparts will be ordered from a high quality external service as siRNA.

9. mRNA extraction. The bone material designated for molecular testing will be stored at $-80^{\circ} \mathrm{C}$. Prior to RNA isolation, the bones will be mechanically powdered in liquid nitrogen. Total
RNA obtained from the bones and also from the cultured cells will be extracted, quantified and stored at $-80^{\circ} \mathrm{C}$. Real time RT-PCR will be used to measure gene expression and the levels of specific miRNA in the bones and MC3T3-E1 cells.

10. GFP labelling of exosomes and extraction. A lentivector-based method expressing CD63, CD9 or CD81 fused to GFP will be applied to the staining of the exosomes. These vectors will be used for transfections of MSCs to produce green exosomes. The green exosomes will be extracted with an Exosome Isolation Kit.

Other lentivirus system vectors will be used to clone selected miRNA, which will be used in the constitutive production of agomirs and antagomirs. The vectors will be used for transfection, viron production in $293 \mathrm{~T}$ cell line packing cells and the transduction of MSCs.

11. Fluorescent microscopy, confocal microscopy. Examination of the fluorescently labelled cells/exosomes will be carried out using fluorescence and confocal microscopy. Flow cytometry finds particular application for testing exosome purity and the presence of GFP and Cy5.

12. Matrix mineralisation will be detected by alizarin red S (ARS) staining. The cells will be stained with calcium alizarin red staining kits and quantified by spectrophotometer. The results of Alizarin Red staining will be expressed as $\mathrm{ng} / \mathrm{mg}$ protein.

\section{Measurable Effects and Expected Results}

In step I the interference of methylprednisolone and exercise, or diclofenac and exercise, on the mice's bone structure, composition and mechanical strength will be determined.

In step II an anti-demineralisation miRNA will be selected in osteoblast cells in culture.

In step III exosomes containing selected anti-demineralisation miRNA will be produced.

In step IV exosomes will be injected into mice to achieve transient stimulation of bone rebuilding.

In step V exosomes will be efficiently produced in vector-transduced cell lines.

\section{Acknowledgements}

Conflict of interest statement

The authors declare no conflict of interest. 


\section{Funding sources}

There are no sources of funding to declare.

\section{References}

1. Siebler T, Robson H, Shalet SM, Williams GR. Dexamethasone inhibits and thyroid hormone promotes differentiation of mouse chondrogenic ATDC5 cells. Bone. 2002;31(4):457-64.

2. Hant FN, Bolster MB. Drugs that may harm bone: Mitigating the risk. Cleve Clin J Med. 2016;83(4):281-8.

3. Hartmann K, Koenen M, Schauer S, Wittig-Blaich $\mathrm{S}$, Ahmad M, Baschant $\mathrm{U}$, et al. Molecular Actions of Glucocorticoids in Cartilage and Bone During Health, Disease, and Steroid Therapy. Physiol Rev. 2016;96(2):409-47.

4. Loi F, Cordova LA, Pajarinen J, Lin TH, Yao Z, Goodman SB. Inflammation, fracture and bone repair. Bone. 2016;86:119-30.

5. Kurmis AP, Kurmis TP, O'Brien JX, Dalen T. The effect of nonsteroidal anti-inflammatory drug administration on acute phase fracture-healing: a review. J Bone Joint Surg Am. 2012;94(9):815-23.

6. Zimmermann EA, Gludovatz B, Schaible E, Busse B, Ritchie RO. Fracture resistance of human cortical bone across multiple length-scales at physiological strain rates. Biomaterials. 2014;35(21):5472-81.
7. Nair AK, Gautieri A, Chang SW, Buehler MJ. Molecular mechanics of mineralized collagen fibrils in bone. Nat Commun. 2013;4:1724.

8. Derry S, Conaghan P, Da Silva JA, Wiffen PJ, Moore RA. Topical NSAIDs for chronic musculoskeletal pain in adults. Cochrane Database Syst Rev. 2016;4:CD007400.

9. Moghadam-Kia S, Werth VP. Prevention and treatment of systemic glucocorticoid side effects. Int $\mathrm{J}$ Dermatol. 2010;49(3):239-48.

10. Benkhadra K, Mohammed K, Al Nofal A, Carranza Leon BG, Alahdab F, Faubion S, et al. Menopausal Hormone Therapy and Mortality: A Systematic Review and Meta-Analysis. J Clin Endocrinol Metab. 2015;100(11):4021-8.

11. Russo CR. The effects of exercise on bone. Basic concepts and implications for the prevention of fractures. Clin Cases Miner Bone Metab. 2009;6(3):223-8.

12. Santos L, Elliott-Sale KJ, Sale C. Exercise and bone health across the lifespan. Biogerontology. 2017;18(6):931-946.

13. Jing D, Hao J, Shen Y, Tang G, Li ML, Huang SH, et al. The role of microRNAs in bone remodeling. Int $\mathrm{J}$ Oral Sci. 2015;7(3):131-43.

Acceptance for editing: 2019-11-09 Acceptance for publication: 2019-12-30 